\title{
Road water damage control and slope protection along the river
}

\author{
Jiachen Liu ${ }^{1, a^{*}}$, Weiping Tian ${ }^{1, b}$, Jiachun Li ${ }^{1, \mathrm{c}}$, Qifeng Liu ${ }^{1, d}$ \\ Highway school, Chang'an University, Xi'an, Shanxi, China, \\ a:1160873349@qq.com_b:306788963@qq.com \\ c:452767128@qq.com_d:793632329@qq.com
}

Key words: road water damage, roadbed, prevention and control measures

Abstract: The road along the river in general water scouring, scour, soak for a long time, leading to the highway subgrade, slope and the corresponding protection engineering deformation and collapse, gradually lost its original functions.To water damage roadbed stability analysis and control countermeasure research, from the aspects of environment, design, construction, maintenance and other analyses the macro factors affecting highway roadbed along the river water damage; Flow from river compression, concave bank erosion, scour and top pick flow or oblique impact and analyzed the main reason for the mountainous area highway roadbed water damage.Along the river road water damage defined the type of road surface and roadbed of hazard-affected bodies and slope erosion protection engineering, this paper introduces the different types of subgrade water damage prevention and control technology, mainly introduced the stone cage, riprap, geotextiles and other measures, and aims at the common subgrade water damage form, put forward the corresponding engineering protection measures and non-engineering protective measures.

\section{Road water damage is introduced and the common road water damage form}

\section{Introduce road water damage}

Road water damage is a serious natural disasters, belong to the category of hydrosphere disaster and to disaster, usually refers to the highway itself and its affiliated structures by storm, flood damage phenomenon and process.In a narrow sense, road water damage refers to flood caused by highway construction of various types, different degree of damage, storm, flood formation factors is the "water", but in fact, the "water" is the key factor of road water damage, rather than the only factor.The term "road water damage", is a natural disaster damage to the highway system of highway facilities collectively, means in the role of all internal and external forcings, highway facilities damaged disasters phenomenon.So, should also include road water damage water along the highway plays the leading role of landslide, collapse, debris flow, pavement, roadbed subsidence and sliding were geological disasters. Visible, general road water damage refers to: in the natural factors (hydrological geology, climate, etc.) and unreasonable human activities under the combination of a series of engineering damage phenomenon happened along the road and the process.

\section{The river road water damage disaster risk is introduced}

Highway engineering has its particularity, water damage disaster hazard-affected body is human creation tangible wealth, namely road building.From the Angle of the highway engineering, the river road water damage disaster risk is defined as: within A certain range along the road and time, different frequency along the river road water damage disasters for highway engineering may cause the phenomena of the loss (including the engineering structure, the human life and property 
and economic activity, etc.), can be expressed as: $\mathrm{R}=\mathrm{f}(\mathrm{H}, \mathrm{A}, \mathrm{V})$.Among them, the $\mathrm{R}$ (risk) refers to the specific river road water damage disaster risk; H (hazard) refers to the area along the river road water damage disaster risk A (affected body) by along the river road water damage disaster threat refers to A specific range of objects, generally refers to the body such as highway along the river and affiliated facilities thereof; $\mathrm{V}$ (vulnerability) refers to the threatened the vulnerability of the object.As you can see, the area along the river road water damage disaster risk $(H)$ and threatened object of vulnerability (V) (A) common size determines the area along the river road water damage disaster losses, is to control the wind along the river road water damage disasters (R) of the basic factors.Therefore, the direction of future along the river road water damage prevention should be through survey highway water damage location, natural conditions, to set up a mountain road along the river water damage of large database, and combining with the GIS system, provide support for future rapid rescue.

\section{Comon form road water damage \\ Road water damage}

In general, the road water damage mainly has the following situation: one is the flood season river water level is too high, water flow on the road, under the effect of longitudinal flood and water erosion, the pavement partial or most of the damage;Second, embankment collapse, leading to the road damage occurred;Three was based pavement protection installations, protective structure deformation, instability, causing the subgrade filling water scour, cause road surface crack, deformation, even collapse.

\section{Roadbed water damage}

Common subgrade water damage are: (1) under the effect of water flooding, erosion, slope sliding, a larger along the river embankment slope deformation and collapse, prompted a gap, the subgrade slope damage, serious when, can cause the subgrade half or even all of water damage, (2) retaining wall, slope protection is caving, instability, collapse, causing the roadbed water damage.

\section{Water damage protection engineering}

Most mountain highway along the river will according to actual condition, the construction of corresponding scour protection engineering to improve subgrade slope erosion resistance;At the same time, in order to ensure the protection engineering of solid foundation, stability, and often near the roadbed slope toe spur dike and dam construction, apron slope protection engineering, etc. When these protective engineering water damage occurs, the collapse of instability, losing some or all of the protective function, could lead to the road surface and roadbed were damaged.Survey found that the most common protective engineering water damage are: (1) slope protection engineering, retaining wall, slope protection, etc.) based caving by water, basic dangling protection engineering of shape, craze, its stability is reduced, but did not collapse, (2) the slope protection engineering, retaining wall, slope protection, etc.) partial or whole damaged, lose protection, lead to subgrade slope directly impacted by water, washing, causing the roadbed damaged, (3) slope toe protection damage (apron, spur dike, etc.), or even lose their protection, a threat to the retaining wall, slope and the stability of the roadbed along the river.

\section{The river road water damage easy to happen}

(1) the river could erode subgrade sections.(1) along the river bend concave bank.(2) mutations spur, stones and other terrain section.(3) the mountains open river and piedmont zone change river sections.(4) have tributaries into sections.

(2) the roadbed compression or encroach on river road.

(3) cross-sectional slope is relatively gentle river road along the river. 
(4) other developing road.

Along the river road water damage control and slope protection technology Along the river road water damage prevention and control of the physical technology and slope protection

Attaches great importance to the basic data collection and analysis;Comprehensive implementation of disaster prevention management;To establish early warning forecast system;Overall arrangement engineering rescue work;Perfect emergency security system.

The river road water damage control and slope protection engineering technology classification

Mountainous area highway subgrade there are many types of scour protection engineering model, according to its effect on the flow of the different ways, can be roughly divided into:

\section{Direct protection installations}

This kind of structure directly attached to the embankment itself, well flow setting, less interference on the natural flow of water, have little impact on upstream and downstream and the other side flow, more suitable for mountain canyon river highway roadbed protection.Mainly including stone retaining wall, slope protection and slope protection plant, as well as the subgrade slope toe and retaining wall foundation spats projects, such as riprap slope foot or pile of stone, apron, stone cage, plasma build by laying bricks or stones block water dam along in the direction of flow, such as setting the spats engineering). Once this kind of protective engineering was washed away by the flood, will immediately endanger embankment safety, belong to the passive protection forms.

\section{Indirect protection installations}

Refers to all kinds of flow, diversion structures, such as spur dike, along the dam, dam, etc.Them by changing the flow structure, the flow deviation is protective line the Banks of the river, or make the Banks may be washed into alluvial river, thereby, make the coastal embankment protection, purpose of subgrade protection. This kind of protection installations protection effect is obvious, even if the flood protection installations local damage, such as head of groyne, also not immediately endanger embankment safety.So, such protection installations can be regarded as active protection forms.

\section{Common subgrade protection project}

\section{Pulp build by laying bricks or stones flaky slope protection}

When the road is located in the river section is wide and straight section of river, the river flow velocity is small, the current scour is lighter, can use pulp build by laying bricks or stones flaky (stone) revetment type, improving impact resistance of the subgrade slope surface.Plasma build by laying bricks or stones, flaky (stone) the basis of slope protection should be buried under the maximum scour depth;If there is the bedrock exposed, its base can be placed on the bedrock with cement mortar and firm connection.

\section{Riprap protection}

In the region is rich in stone, when the flow rate of $3 \mathrm{~m} / \mathrm{s}$ or higher, plant protection and stone protective invalid, riprap protection can be used.The ripped-rock is not affected by climate, heavy fact can before construction, seasonal flooding or long-term flooding all can use.Riprap slope, should not be steep in the natural Angle of repose of the ripped-rock after flooding, the slope rate of general $1.52 .0 \mathrm{~m}$, slope ratio $\mathrm{n} 1.252 .0$. The particle size of stone, as a general rule, be $15-20 \mathrm{~cm}$.

\section{Gabion protective}

In areas rich in stone, when the flow velocity at or above $5.0 \mathrm{~m} / \mathrm{s}$, the use of gabion protective, also can use local materials, bamboo cage protection.Gabion woven wire frame, the rock fill, is 
located in the slope toe, just in case the rapids and big waves destroyed embankments, can also be used to reinforce the riverbed, prevent scour.Cage stone size should not be less than $4 \mathrm{~cm}$, usually for 5 -- $20 \mathrm{~cm}$, outer with outstanding big stone edges and corners, the inner small stones are available.Wire frame is usually rectangular or circular.Stone cage Settings, used to prevent scour tao bottom, should be flat and vertical slope toe the line, and one end fixed and the other end is not fixed, and when used to prevent bank slope erosion, spread into a trapezoid.

\section{Geotextiles soft mattress}

Geotextiles is soft mattress on geotextiles with stone or precast concrete block revetment structure weight.Commonly used in underwater engineering and is expected to scour the river bed and bank slope soil surface may occur.Divided into single chip pad and a double pad.Applying geotextile mould bags of steep slope not to $1: 1$, underwater construction, water flow speed is not more than $1.5 \mathrm{~m} / \mathrm{s}$. Geotechnical mold bag is a kind of double cloth bag, bag filling liquid concrete or cement mortar or small particle size of stone concrete and high-strength scleroma plate after solidification. When coarse aggregate concrete filling the following table, slump should not be less than $20 \mathrm{~mm}$, strength grade of no less than c10, filling slurry, the strength grade of no less than M2.5.

\section{Spur dike}

Spur dike stretched into the river, occupy part of the river section, by changing the flow structure, the flow deviation is protective embankment or will scour area into a deposition area, so as to achieve the goal of scour protection.Spur dike along the river road roadbed protection construction, mainly have the effect of two aspects: one is the revetment is given priority to, for short spur dike swarm, more commonly used to prevent water harmful to the Banks of the river or subgrade scour, it only change the local in the direction of flow, don't change the direction of the mainstream;2 is give priority to in order to adjust the water flow, by mainstream pick flow changes the flow direction, make it far away from the protection of the Banks or subgrade, long spur dike.No matter adopt what kind of spur dike, its role is to prevent the water to the harmful scour of subgrade.

\section{Conclusion}

Papers are not exist in the following research, it is suggested that further in subsequent research work:

(1) along the river highway subgrade water damage are the result of interaction of many factors, the cause of the subgrade water damage involves many aspects, and is quite complicated, the influence factors of the subgrade stability is numerous, the thesis involves only a part of the main factors, and need further research, so as to make the results more comprehensive and scientific and reliable.

(2) the future development direction of along the river road water damage should emphasize to the identification of road water damage, using GIS system and of the construction of the unmanned aerial vehicle (uav) together, the uav image processing, to simplify search process in reality, especially in disasters occur, can the rapid repair of highway.

\section{Reference}

[1] Huanzhang Jiang. Road water damage prevention (1) - road water damage prevention and cure problems [J]. Highway, 1986 (1) : 42-46; 
High winter light. [2] of water damage prevention and control of highway and bridge [M]. Beijing: people's traffic press, 2002. 7.

[3] Jia-chun Li, li-zhen Huang, wei-ping Tian, etc. Highway natural disaster classification [J]. Journal of chang 'an university (natural science edition), 2011, 31 (2) : 33-37;

[4] huan-fang Liu. Corner free surface shape research [J]. Journal of water conservancy, 1990, 21 (4) : 46-50;

[5] Hong-kai Chen, hong-mei Tang, an albino. Mountainous area highway roadbed damaged by flood development mechanism research - in sichuan province highway roadbed damaged by flood, for example [J]. Journal of chongqing jiaotong institute, 1994 (4) : 34-39;

[6] Wei-ping Tian. Bend circulation and roadbed along the river scouring experiment research [J]. Journal of chongqing jiaotong institute, 2002, 21 (3); 